\title{
IDENTIFICATION OF STUDENTS' MISCONCEPTIONS IN STATIC FLUID
}

\author{
Haritsah Alfad \\ D3 Farmasi, Akademi Farmasi Putra Indonesia Malang \\ Email: haritsahalfad.akfar.pim@pimedu.ac.id \\ Website: http://jurnal.uin-antasari.ac.id/index.php/jtjik \\ Received: 9 September 2019; Accepted: 20 June 2020; Published: 30 June 2020
}

\begin{abstract}
This study aimed to identify students' misconceptions in static fluid covering Archimedes' Principle and hydrostatic pressure. The used-instruments were of 10 multiple choice questions supported by reasons for answers. The method used in this research was giving the exercise in the form of questions to 32 students of XI class who had received subject matter of Archimedes' Principle and hydrostatic pressure at middle and high school levels. The results of the students' answers were then analyzed and presented qualitatively and quantitatively. Based on the analysis of students' answers obtained 16 types of misconceptions in static fluid. In comprehending Archimedes' Principle, most students experienced difficulties in determining the state of floating, sinking and determining magnitude of buoyancy of objects in a fluid. While on hydrostatic pressure topic, most students found it difficult to determine the amount of hydrostatic pressure at a point in the fluid.
\end{abstract}

Key Words: Archimedes’ principle, misconception, static fluid

\section{INTRODUCTION}

Speaking about physics learning, there are still found some students who have difficulties in mastering the learning materials that some studies revealed the students experienced difficulties in physics material, particularly in static fluid which is leaded them to misconceptions. This fact is supported by upfront research which explores students' difficulties in comprehending the static fluid concept such as their misconceptions upon Archimedes' principle which are the concept of floating and submerged, the buoyant force, and the volume of water displaced. (M.E. Loverude, Heron, \& Kautz, 2010; Yin, Tomita, \&Shavelson, 2008) and misconceptions on hydrostatic pressure (Goszewski, Moyer, Bazan, \& Wagner, 2013; ME Loverude et al., 2010).
In particular, physics consists of a collection of interrelated concepts so if one concept is not fully comprehended or passed, consequently it will be difficult to understand the advance concept (Ornek, Robinson, \& Haugan, 2008). The same thing was also stated by Anderson (Chen, 2011) that to learn effectively, students must organize their prior insights with their new ones, hence if students experience misconceptions, they will be hard in understanding the upcoming materials.

This study aimed to identify students' comprehension of concepts and difficulties in the form of misconceptions on static fluid material. As a result of this study, it is expected to provide a foundation for teachers in overcoming students' difficulties on the afromentioned material, thus the students will respond to 
the misconceptions and lead them to a scientific understanding.

\section{RESEARCH METHOD}

This research is a qualitative descriptive with stages of problem formulation, research sample selection, instrumentation, data collection, data analysis as well as conclusion drawing. The test instrument given in the form of multiple choice questions supported by reasons. This instrument was adapted from several previous studies that have been used by experts (Goszewski et al., 2013; M. E. Loverude et al., 2010; Ünal \& Coştu, 2005; D. J. Wagner, Cohen, \& Moyer, 2009; Doris J Wagner, Carbone, \& Lindow, 2014; Wong et al., 2016).

Next, the results of data instrumens were analyzed by grouping the results of students' answers based on the similarity of their explanation. Due to the results of grouping, the types of misconceptions experienced by students were obtained. Then, this study also grouped the number of students who experienced misconceptions in each type.

The subjects in this study were 32 students of XI Science (MIA) class of Senior High School (SMAN) 1 Malang in semester 2. Students had obtained subject material on hydrostatic pressure and Archimedes' principle in the VIII class (Junior High School) and the X class (Senior High School). The material of this research focused on afromentioned materials which were stated by the experts in their research that students often experienced numerous misconceptions..

\section{FINDING AND DISCUSSION}

Test instruments in this study amounted to 10 questions presented in Picture 1 and 2. Then, students' answers were analyzed and categorized on the order of misconception types that are summarized in Table 1. Students' empty and blind-conception answers were not counted in the percentage of students' answers.

\section{A. Archimedes' Principle}

\section{Question 1}

In this question, students are asked to identify the position of floating object which was divided into different sizes (Picture1).

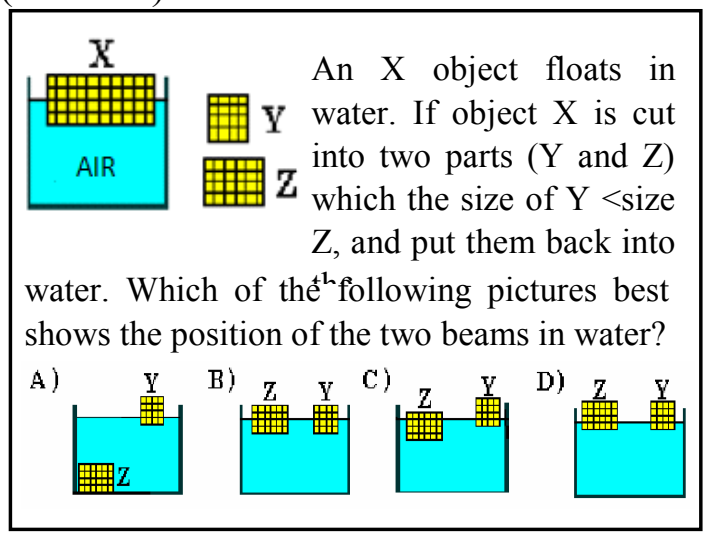

Picture 1. Question 1 in the test instrument of Archimedes' Principle

The number of students who answered right (B) was $25 \%$, then $44 \%$ of the total number were either choosing answer $\mathrm{A}$ or C. It indicated that the students' misconception in this case was the object 's weight affected the floating and sinking states $(31 \%)$, then the rest $(13 \%)$ considered that the divided-object will change its density. Similar results were shown by previous studies (Ünal \& Coştu, 2005), students experienced a misconception that weight or mass affects the floating state and sinking of objects in the fluid.

\section{Ouestion 2}

$28 \%$ of total sample students answered correctly in line with the concept that fluid volume moved by a ball depends on its object volume immersed in fluid (Picture 2). While 53\% of students experienced a misconception that fluid volume transferred by the ball depends its density of the fluid. Students understood that the density of oil is smaller than water and the largest density is steel balls, however, most of them assumed that oil 
will float the ball higher causing the level of oil in measuring cylinder is higher than the water level. This is similar to the misconception that an object will float higher in a fluid with a small density. (Wong et al., 2016).

\begin{tabular}{|c|}
\hline $\begin{array}{l}\text { Two measuring- } \\
\text { cylinders each filled } \\
\text { with water and oil at } \\
\text { the same level. Two } \\
\text { steel balls with the } \\
\text { same volume and }\end{array}$ \\
\hline
\end{tabular}

Picture 2. Question 2 in the test instrument of Archimedes' Principle

\section{Question 3}

A minority of students $(6 \%)$ answered correctly the concept that the state of floating and sinking objects in a fluid depends on the relative ratio of the density of objects to density of fluids in question number 3 (Picture 3 ).

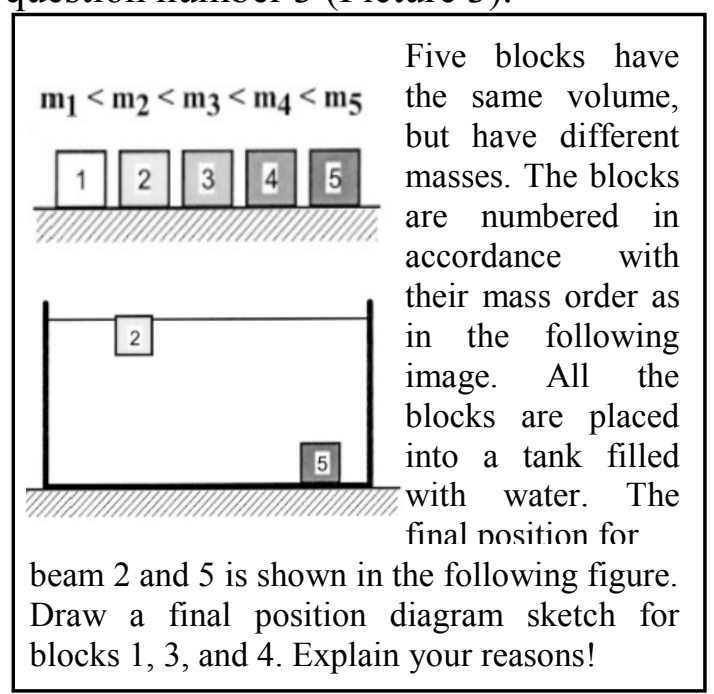

Picture 3. Question 3 in the test instrument of

$$
\text { Archimedes' Principle }
$$

The important information for this question is Beam 2 is slightly floating in water which indicates if the density of beam 2 is close to the density of water, thus beam 3 could either drift or sink. Most students (88\%) drew a descending line diagram and one of the students answered: "Since the beam volume is the same, the density of the beam is comparable to the mass. he position of beam 3 is between beam 2 and 4, while beam 4 is between beam 3 and 5 ". Thus, this misconception is in line with the finding of previous studies. (Michael E. Loverude, Kautz, \& Heron, 2003; D. J. Wagner et al., 2009).

\section{Question 4}

$38 \%$ of students answered by changing the volume of water in a tank to change the buoyancy in question number 4 (Picture 4). While 19\% of students thought that changing the length of the rope can change the buoyancy. A previous study (Doris J Wagner et al., 2014) revealed several students' misconceptions in this case, such as they assumed that the magnitude of buoyancy is comparable to depth and the rest is inversely comparable to depth. While $28 \%$ of students assumed that reducing the mass of objects can increase the buoyancy force. Hence, this is the same as the idea that the smaller the density of objects, the more they will be floated.

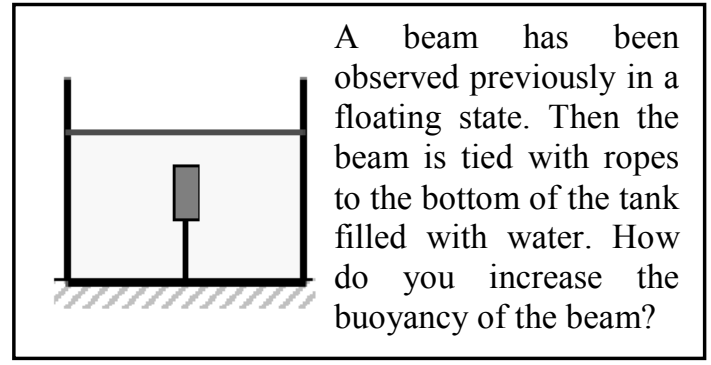

Picture 4. Question 4 in the test instrument of Archimedes' Principle

\section{Question 5}

In question number 5 (Picture 5), the majority of students (53\%) experienced a misconception that the size of buoyancy force was inversely proportional to depth (Doris $\mathrm{J}$ Wagner et al., 2014). One of the students answered by "the buoyancy force at beam $A$ and $B$ 
is since it is located at the bottom of the aquarium, while the buoyancy force at beam $C$ is greatest because of its higher position" While several students answered the buoyant force on beam $\mathrm{C}$ was the smallest due to the influence of the rope tension force and the minority of students $(6 \%)$ gave an unexpected answer that the magnitude of the buoyancy force for beams $\mathrm{A}$ and $\mathrm{B}$ is equal to zero for They assumed that buoyancy only exists (more than zero) if the object is floating or drifting.

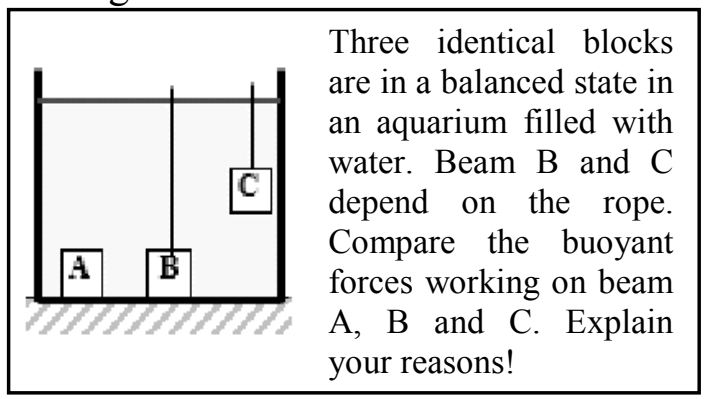

Picture 5. Question 5 in the test instrument of Archimedes' Principle

\section{Question 6}

In this case, three identical beams of volume are sinking (Picture 6).

\begin{tabular}{|l|l|}
\hline & $\begin{array}{l}\text { Three blocks with the } \\
\text { same shape and volume, } \\
\text { but have different } \\
\text { masses, MA }>\mathrm{MB}>\mathrm{MC} \\
\text { is located at the bottom } \\
\text { of the aquarium filled }\end{array}$ \\
with oil. Compare the buoyant forces \\
working on beam A, B and C. Explain your \\
reasons!
\end{tabular}

Picture 6. Question 6 in the test instrument of Archimedes' Principle

Half of students $(50 \%)$ answered that the amount of buoyancy is directly proportional to the mass of the object. Since the mass of beam A is greatest, the buoyancy force on beam $A$ is greatest $(\mathrm{FA}>\mathrm{FB}>\mathrm{FC})$. Then, $16 \%$ of students answered the buoyancy force for the three beams are the same because they are located on the same level. This answer is similar to problem presented in question 5 , however, there is no student gives an answer that the magnitude of the buoyancy force is zero. This answer is similar to problem 5 , but no student gives an answer that the magnitude of the buoyancy force is zero.These misconceptions are similar to the results of particular previous studies. (Doris J Wagner et al., 2014).

\section{B. Hydrostatic Pressure Question 1}

In question number 1 (Picture 7), students are asked to choose a greater pressure than the pressure at the point $X$ in the available picture. $13 \%$ of students answered with the correct concept (option B) that the amount of hydrostatic pressure is directly comparable to the depth of fluid surface. Next, several students (38\%) chose option E since they assumed that narrower the container, it will put the greater pressure. $16 \%$ of students chose option D because they assumed that the pressure at point $\mathrm{D}$ is greater since it gets pressure from a floating object. After that, a small proportion of students $(6 \%)$ chose option $\mathrm{F}$ because they have an assumption that the greater amount of water volume causing the greater pressure. This misconception showed that students thought hydrostatic pressure is proportional to the weight of the fluid. (Goszewski et al., 2013).

\section{Question 2}

The case in this question (Picture 8 ) is the adaptation of the test instrument to a double barometer. (M. E. Loverude et al., 2010). This question displayed an open manometer connected by a gas cylinder, then students are asked to choose the right option with a proper reason. Some students $(16 \%)$ answered correctly with option A that hydrostatic pressure at points of equal level are the same. While $41 \%$ of students chose option B that indicated in one of the students' answer: "the pressure at point $A$ is smaller than point $B$ because the density of the gas is smaller than mercury's". They tried to 


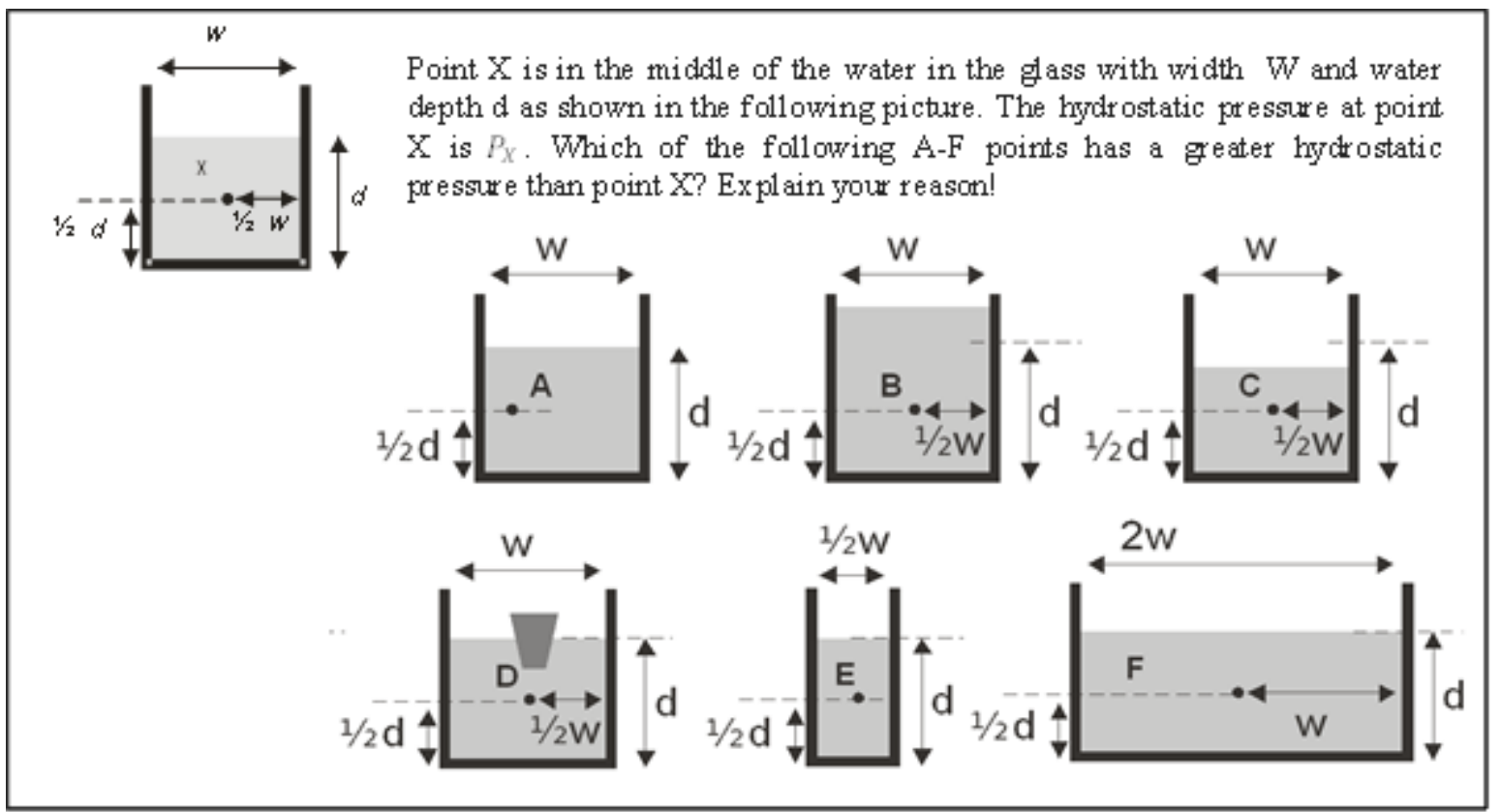

Picture 7. Question 1 in the test instrunent of Hydrostatic Pressure

relate the density and hydrostatic pressure. A small percentage of students $(9 \%)$ chose the option $\mathrm{C}$ (the pressure at point $\mathrm{D}$ and $\mathrm{C}$ is the same). Based on students' explanations for the option, it was found that students ignored the gas pressure above point $\mathrm{D}$ since students only calculated the height of the fluid column above points $\mathrm{D}$ and $\mathrm{C}$, where the mercury column height above that point was the same.

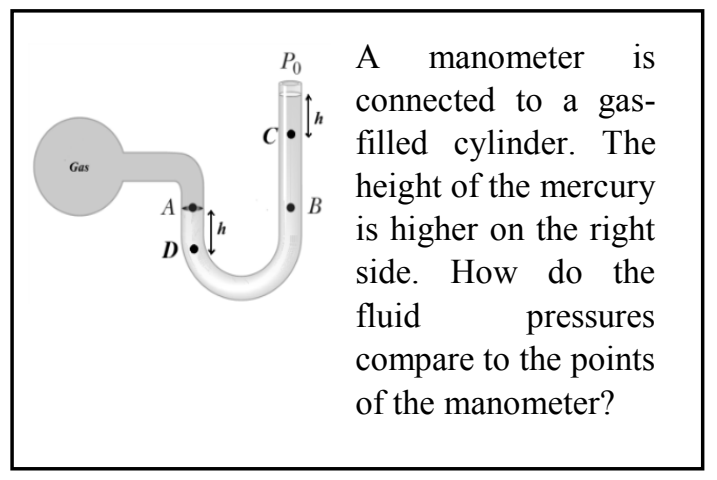

Picture 8. Question 2 in the test instrunent of Hydrostatic Pressure

\section{Question 3}

This question (Picture 9) presented the connected-vessel and $31 \%$ of total students answered with correct answer followed by correct explanation. Then, $34 \%$ of students answered that the pressure in $\mathrm{A}$ was the smallest and $\mathrm{C}$ was the biggest one.

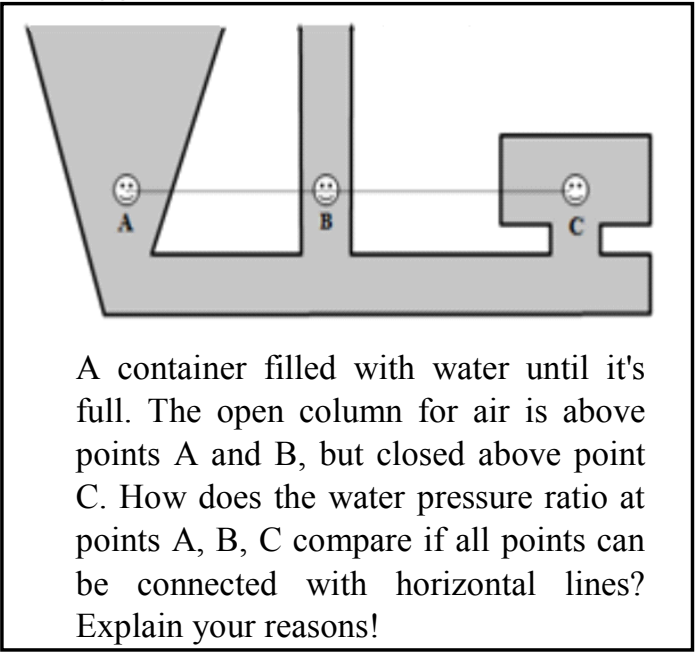

Picture 9. Question 3 in the test instrunent of Hydrostatic Pressure

In details, students explained the pressure in $\mathrm{C}$ is the biggest since it is a confined space, whereas point $\mathrm{B}$ is in the narrow open column and point $\mathrm{A}$ is in the wide open column. A small proportion of students (9\%) gave the answer of pressure on $\mathrm{A}$ which is the biggest and $\mathrm{C}$ is the smallest. Students explained the pressure at $\mathrm{A}$ is the greatest because the volume of 
fluid above A is more than above points B and C. From the answers obtained, students tend to make the wrong conclusion that the hydrostatic pressure is proportional to the amount of fluid volume above a point. This answer is similar to the test instrument option from the results of a previous study (Goszewski et al., 2013).

\section{Question 4}

An object in a fluid will get a force or hydrostatic pressure from all directions. Balloons that are put in water remain round while the volume is shrinking. (Goszewski et al., 2013). A small percentage of students (9\%) answered the questions correctly,then as many as $38 \%$ of students answered with flat oval balloons and the volume was shrinking due to fluid pressure from above. While $25 \%$ of students answered the shape and volume of the balloon remained because the fluid pressure had no effect on it. Based on the answers of these students, it obviously can be seen that students did not understand the concept of the direction of pressure in the fluid for they generalized the concept of fluid pressure with general pressure. Moreover, pressure is generally defined as the quotient of forces with contact area, so students thought that objects in fluid are subject to gravity by the volume of water above them.

Table 1. The results of misconceptions on static fluid with a percentage $>10 \%$

\begin{tabular}{lll}
\hline M & \multicolumn{1}{c}{ Description of Misconceptions } & $\%$ \\
\hline M1 & The state of floating and sinking is influenced by the weight of the object & $31 \%$ \\
\hline M2 & The density of objects changes if the volume of objects changes & $13 \%$ \\
\hline M3 & $\begin{array}{l}\text { The volume of fluid displaced by a submerged object depends on the density of } \\
\text { the fluid. }\end{array}$ & $53 \%$ \\
\hline M4 & $\begin{array}{l}\text { The state of an object floating or submerged in a fluid depends on the relative } \\
\text { ratio of density between objects. }\end{array}$ & $88 \%$ \\
\hline M5 & The buoyancy force depends on the volume of the fluid. & $38 \%$ \\
\hline M6 & The buoyancy force is directly proportional to the depth of the object. & $19 \%$ \\
\hline M7 & The buoyancy force is inversely proportional to the mass of the object. & $28 \%$ \\
\hline M8 & The buoyancy force is inversely proportional to the depth of the object. & $53 \%$ \\
\hline M9 & The buoyancy force is inversely proportional to the mass of the object. & $50 \%$ \\
\hline M10 & The same buoyancy force for objects located at the same level. & $16 \%$ \\
\hline M11 & Hydrostatic pressure depends on the size of the container. & $38 \%$ \\
\hline M12 & Hydrostatic pressure is influenced by floating objects. & $41 \%$ \\
\hline M13 & Hydrostatic pressure at points on the horizontal plane is not the same. & $34 \%$ \\
\hline M14 & Hydrostatic pressure in a closed space is greater than an open space. & $38 \%$ \\
\hline M15 & Objects in the fluid are subjected to hydrostatic pressure from above. & $25 \%$ \\
\hline M16 & $\begin{array}{l}\text { Hydrostatic pressure does not affect the shape and volume of objects in the } \\
\text { fluid. }\end{array}$ & \\
\hline
\end{tabular}

\section{CLOSURE}

The results of this study found 16 types of students' misconceptions on static fluid material. Generally, these misconceptions were also found in previous studies. In the material of Archimedes' principle, most students have difficulties in determining the state of floating and sinking as well as determining the magnitude of the buoyancy of objects in fluid (M1-M10). On hydrostatic pressure material, most students find it difficult to determine the amount of hydrostatic pressure at the point in the fluid (M11-M16).

Furthermore, the phenomenons in the material of static fluids that are often encountered such as the state of floating, sinking and the pressure by stationary fluid. Additionally, to understand static fluid material, students need to fully comprehend in analyzing forces such as buoyancy, weight and pressure from fluids. Therefore, 
provision of practicum and simulation accompanied by exercises to analyze the force are expected to lessen or diminish students' misconceptions on static fluid material.

\section{REFERENCES}

Chen, L. H. (2011). Enhancement of student learning performance using personalized diagnosis and remedial learning system. Computers and Education.

https://doi.org/10.1016/j.compedu.20 10.07.015

Goszewski, M., Moyer, A., Bazan, Z., \& Wagner, D. J. (2013). Exploring student difficulties with pressure in a fluid. AIP Conference Proceedings, $1513,154-157$.

https://doi.org/10.1063/1.4789675

Loverude, M. E., Heron, P. R. L., \& Kautz, C. H. (2010). Identifying and addressing student difficulties with hydrostatic pressure. American Journal of Physics, 78(1), 75-85. https://doi.org/10.1119/1.3192767

Loverude, Michael E., Kautz, C. H., \& Heron, P. R. L. (2003). Helping students develop an understanding of Archimedes' principle. I. Research on student understanding. American Journal of Physics. https://doi.org/10.1119/1.1607335

Ornek, F., Robinson, W., \& Haugan, M. (2008). What Makes Physics
Difficult. Science Education International, 18(3), 165-172.

Ünal, S., \& Coştu, B. (2005). Problematic issue for students: Does it sink or float? In Asia-Pacific Forum on Science Learning and Teaching (Vol. 6). Retrieved from https://www.researchgate.net/publica tion/26411488

Wagner, D. J., Cohen, S., \& Moyer, A. (2009). Addressing student difficulties with buoyancy. AIP Conference Proceedings, 1179, 289292. https://doi.org/10.1063/1.3266739

Wagner, Doris J, Carbone, E., \& Lindow, A. (2014). Exploring Student Difficulties with Buoyancy. 357-360. https://doi.org/10.1119/perc.2013.pr. 077

Wong, D., Lim, C. C., Munirah, S. K., Foong, S. K., Hadjiachilleos, S., Valanides, N., ... Yeary, S. A. (2016). Student and Teacher Understanding of Buoyancy. 0693(March 2016), 4-7. https://doi.org/10.1080/02635143.20 13.811074

Yin, Y., Tomita, M., \& Shavelson, R. (2008). Diagnosing and Dealing with Student Misconceptions: Floating and Sinking. Science Scope, 31(8), 34-39. Retrieved from https://www.questia.com/library/jour nal/1G1-179076820/diagnosing-anddealing-with-student-misconceptions 